\title{
Recent advances in peptic ulcer bleeding
}

\author{
Ian LP Beales
}

Address: Gastroenterology Department, Norfolk and Norwich University Hospital, Norwich, Norfolk NR4 7UZ, UK

Email: i.beales@uea.ac.uk

FI000 Medicine Reports 2009, I:44 (doi:10.3410/MI-44)

The electronic version of this article is the complete one and can be found at: http://FI000.com/Reports/Medicine/content/I/44

\begin{abstract}
Peptic ulcer bleeding remains a common cause of hospital admission, morbidity and mortality. Data published since 2006 illustrate that assessment, endoscopic and pharmacological management, and follow-up strategies can be refined to improve the overall prognosis of peptic ulcer bleeding.
\end{abstract}

\section{Introduction and context}

Acute upper gastrointestinal bleeding remains an important medical emergency. A recent large nationwide audit in the UK $(6,750$ cases $)$ showed that overall rates of admission to hospital were 103 out of 100,000 adults, with an overall mortality of $10 \%$ in new admissions and $26 \%$ in those who have a gastrointestinal haemorrhage whilst an inpatient. Peptic ulcer bleeding (PUB) remains the single most common cause of upper gastrointestinal haemorrhage (36\% of cases) and the UK audit showed a mortality of $3.8 \%$ in patients under 60 years old rising to $10 \%$ in patients over 80 years old [1]. These results are rather worse than those reported in trials in specialist centres and probably reflect the increasing age and comorbidity of patients in the 'real world', as well as the relatively slow spread of optimal practice (for instance, only $6 \%$ of patients had dual endoscopic therapy [1]). Recent studies have further refined our management strategies for PUB and these can be viewed in terms of risk scoring and stratification, resuscitation, endoscopic therapy, pharmacotherapy and prevention.

\section{Recent advances}

\section{Risk stratification and scoring}

The Rockall score is widely used to compare outcomes and is very useful as an audit tool, having been validated in several populations [2]. It performs less well as a guide to management, especially in predicting very low-risk bleeders, who can safely be discharged without hospital admission. The Glasgow-Blatchford score (GBS) was initially shown to be superior in defining this low risk group and a recent validation study in 676 separate patients confirmed that a score of 0 [pulse $<100$, systolic blood pressure $>110 \mathrm{mmHg}$, urea $<6.5 \mathrm{mmol} / \mathrm{l}$, haemoglobin $>13.0 \mathrm{~g} / \mathrm{dl}$ (men) or $12.0 \mathrm{~g} / \mathrm{dl}$ (women), and an absence of syncope, melaena, heart failure or liver disease] was associated with a zero rate of death, transfusion or endoscopic intervention [3]. A Canadian study utilised a modified GBS (omitting urea and syncope) and although effective, it did perform less well than the full score (5\% re-bleeding rate in the 0 scoring group) [4]. Thus, early discharge strategies based on the full GBS scoring system should be implemented to increase efficient use of resources.

\section{Resuscitation}

Whilst prompt and appropriate fluid resuscitation is essential to the effective management of PUB, there are remarkably few data on which to base management and transfusion strategies and these remain essentially clinical decisions. An increasing number of patients with PUB have been treated with vitamin $\mathrm{K}$ antagonists such as warfarin, and the availability of prothrombin complex concentrate (which contains factors II, VII, IX and $\mathrm{X}$ ) is a real advance in the reversal of anticoagulation in such patients [5]. Although never examined specifically in PUB, the rapid and effective reversal of anticoagulation achieved with this agent implies it should be central to the resuscitation of actively bleeding patients on warfarin. 


\section{Endoscopic therapy}

A variety of endoscopic methods are available to treat PUB, with new devices coming to the market regularly. Guidelines recommend the use of injection therapy plus either thermal coagulation or endoclips [6]. Systematic reviews have confirmed that combined therapy is more effective than adrenaline injection alone, but it has not been shown that combined therapy is better than clips or thermal coagulation alone and these two modalities alone were found to be equivalent [7-9].

Two recent studies have examined the efficacy of the newly developed triclip: in both a simulator model [10] and clinical practice, results were worse than with standard clips, mainly because of difficulty in placing this clip accurately [11]. A systematic review confirmed that endoclips are less effective for PUB lesions on the posterior duodenal wall, posterior gastric wall, and lesser curve because of difficulty placing the clips [8].

Adrenaline injection is probably the easiest and most widely available endoscopic technique and may be used alone when other methods are unavailable. The optimal volume of adrenaline for combination therapies is unclear, but recent studies have clarified the dose when used alone. Liou et al. [12] compared 20, 30 and $40 \mathrm{ml}$ of $1: 10,000$ adrenaline (epinephrine). Initial haemostasis was equivalent but the smallest volume was associated with significantly more re-bleeding and the $40 \mathrm{ml}$ dose was associated with an unacceptable perforation rate (6.6\%), suggesting that when used alone, $30 \mathrm{ml}$ would be the optimal dose. Injection regimes were further refined

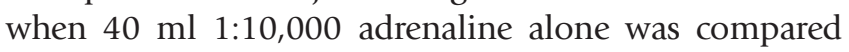
with $40 \mathrm{ml}$ saline alone or enough adrenaline to produce initial haemostasis followed by saline to a total volume of $40 \mathrm{ml}$. Initial haemostasis was higher in both the adrenaline groups (both 98.6\%) than the saline alone group $(88.9 \%)$ but re-bleeding rates were similar (approximately $5 \%$ ). Perforation occurred in $2.8 \%$ of the adrenaline alone group [13]. These volumes are rather higher than most Western endoscopists generally use, but these data should encourage a re-examination of these practices. Although multimodality endoscopic therapies are preferable, when other methods are unavailable, adrenaline followed by saline would seem to be appropriate.

\section{Pharmacotherapy}

Potent acid suppressive therapy to stabilise the fibrin clot in the acute situation has always been an attractive idea and proton pump inhibitors (PPIs) are widely used for this. However, data on the most effective way to use these agents are conflicting. High dose intravenous omeprazole ( $80 \mathrm{mg}$ bolus followed by $8 \mathrm{mg} / \mathrm{h}$ for 72 hours) after endoscopic therapy has been widely used following the landmark study of Lau et al. [14]. However the effects of pharmacodymanics, physiology and Helicobacter pylori infection in the Asian population in that study mean that it may not be generalisable to other groups. A Cochrane systematic review (including the data from Lau et al.) confirmed that PPIs reduce re-bleeding and surgery in PUB but did not show the superiority of any dose or route of administration [15]. The beneficial effects were significantly more pronounced in the studies in Asian populations. One important point is that all the studies in the systematic review used oral or parenteral PPIs at higher than standard ulcer healing doses [15].

Subsequent recent studies examining the effects after endoscopic therapy have only added to the confusion. A retrospective Canadian study of 162 patients [16] showed that oral omeprazole (at least $40 \mathrm{mg}$ ) was as effective as omeprazole infusion following endoscopic haemostasis. A North American trial comparing parenteral high-dose pantoprazole with intravenous ranitidine was stopped early because of slow recruitment [17]; no significant differences were seen, although re-bleeding was numerically lower with pantoprazole (6.9 versus $14.3 \%$ ). A similar randomized study predominantly in Europeans showed that intravenous pantoprazole was not superior to intravenous ranitidine, although rebleeding rates in that study were very low (2.9-3.2\%) [18]. A further trial in India (203 patients) showed that intravenous pantoprazole was superior to placebo, reducing re-bleeding (7.8 versus $19.8 \%$ ) and transfusions [19]. A Greek study of 164 patients showed that intravenous pantoprazole was more effective than somatostatin in preventing re-bleeding (5 versus 17\%) despite equivalent actions on gastric $\mathrm{pH}$ [20]. Thus, it seems that PPI therapy is mandatory for PUB and whilst high dose infusions are very effective in Asian populations, the optimal regimens for Caucasians still need to be established. A recently published large study [21] showed that intravenous esomeprazole bolus (80 mg) followed by infusion for 72 hours $(8 \mathrm{mg} / \mathrm{h}) \mathrm{did}$ significantly reduce re-bleeding (5.9 versus $10.3 \%$ ) and endoscopic retreatment (6.4 versus $11.6 \%$ ) compared to placebo in a predominantly Caucasian population (767 patients) and this may yet become the treatment of choice following endoscopic therapy.

The effect of potent acid suppression before endoscopy has also been investigated. Lau et al. [22] showed that parenteral omeprazole reduced endoscopic stigmata and need for intervention, but a further Cochrane analysis confirmed only that pre-endoscopy PPI reduced highrisk endoscopic stigmata without affecting the clinically important outcomes (mortality, re-bleeding or surgery) [23]. 


\section{Prevention}

It is accepted that $H$. pylori, cyclo-oxygenase inhibitors and antiplatelet drugs are the main remedial causes of PUB. Gisbert et al. [24] confirmed the importance of H. pylori. Following successful eradication (which may require sequential treatment strategies) the rate of rebleeding was only $0.22 \%$ per year and patients did not require long-term acid suppressive therapy. Against this, a systematic review of $H$. pylori testing in PUB [25] showed that all tests except urea-breath testing (sensitivity 93\%), especially biopsy-based ones (sensitivities 45-70\%), had decreased sensitivity in PUB. Faecal antigen testing performed relatively well (sensitivity $87 \%$ ). These studies confirm that strategies to identify, treat and follow up $H$. pylori are essential in the management of PUB.

Although the initial promise of the cyclo-oxygenase-2 (COX-2) selective agents has been tempered by worries about their cardiovascular toxicity and the realisation that they are not without gastrointestinal effects, these agents do offer some advantages in selected patients with regards to PUB. In the colonic adenoma prevention trial, rofecoxib (now withdrawn, but a very selective COX-2 inhibitor) was associated with PUB rates significantly greater than placebo ( 0.23 versus 0.06 per 100 patientsyears), showing these are not a panacea for peptic ulcers [26]. However, a large population-based case-control study confirmed that $\mathrm{COX}-2$ selective agents were associated with lower rates of PUB than traditional nonsteroidal anti-inflammatory drugs (NSAIDs) and residual risk was significantly reduced by co-prescription of a PPI [27].

Previously, celecoxib was shown to be equivalent to diclofenac plus PPI following PUB (re-bleeding rates 4.9 versus $6.4 \%$ ) [28] and an important study, again from Hong Kong, showed that celecoxib plus esomeprazole was better than celecoxib alone following PUB (re-bleeding rates 0 versus $8.9 \%$ ) [29]. There still may be differences between the various cyclo-oxygenase inhibitors but this regimen does offer a way forward for those requiring continued anti-inflammatory therapy after PUB.

Clopidogrel is associated with a significantly increased rate of PUB. Following an aspirin-induced PUB, clopidogrel alone was worse than aspirin plus PPI (re-bleeding rates after 52 weeks, 13.6 versus 0\%) [30].

The addition of clopidogrel to aspirin does increase the absolute risk of PUB in those without a previous history of the condition, by about $1 \%$ per year $(0.3 \%$ increased to $1.4 \%$ ) [31]. In view of this relatively low excess risk and the recent data suggesting that PPIs can significantly reduce the cardioprotective effects of clopidogrel [32], and the lack of proven efficacy for $\mathrm{H}_{2}$-receptor antagonists in this situation [33], primary prophylaxis with a PPI is probably not indicated.

A difficult situation arises in those patients with PUB and a recently inserted coronary stent or unstable coronary syndrome. In these patients, discontinuation of dual antiplatelet agents is associated with a significant risk of adverse cardiovascular events (29\% at 1 month [34]). In a small (88 patients) but important study, Ng et al. [35] showed that when antiplatelets were reintroduced within 1 week of PUB with PPI cover, the re-bleeding rate was $0 \%$ at 3 months. These results require duplication but suggest that antiplatelets can be reintroduced early after cessation of PUB.

\section{Implications for clinical practice}

The GBS score provides a secure evidence base to limit hospital admissions and investigations in low-risk patients. Combined endoscopic therapies are superior to adrenaline alone. When endoclips or thermocoagulation are unavailable, initial adrenaline followed by saline to a total volume of $40 \mathrm{ml}$ seems the optimal injection regimen. Following cessation of bleeding, continued management should include searching for and eradicating H. pylori and strategies to minimise further druginduced PUB. Aspirin combined with a PPI is preferable to clopidogrel following aspirin-induced PUB, and should anti-inflammatory drugs need to be reintroduced in this high-risk group, celecoxib plus esomeprazole seems to be the regimen of choice, bearing in mind cardiovascular risk factors. In the highest cardiovascular risk patients, early reintroduction of antiplatelets seems relatively safe, although further confirmatory studies are required as are further data on the interactions between antiplatelets and PPIs.

PPIs are mandatory after endoscopy in PUB, but the optimal regimen and drug do require further definition, especially in non-Asian patients. The best evidence is for high dose intravenous esomeprazole in this group of patients. High-dose PPI therapy before endoscopy does not affect major clinical outcomes, and should probably be reserved for patients in whom expedient endoscopy is not possible.

\section{Abbreviations}

COX-2, cyclo-oxygenase-2; GBS, Glasgow-Blatchford score; NSAID, nonsteroidal anti-inflammatory drug; PPI, proton pump inhibitor; PUB, peptic ulcer bleeding. 


\section{Competing interests}

The author has received research funding from and served on advisory boards for AstraZeneca, and received funding for educational activities from AstraZeneca, Wyeth Pharmaceuticals and Abbott Pharmaceuticals, all of which manufacture PPIs.

\section{References}

I. UK Comparative Audit of Upper Gastrointestinal Bleeding and the Use of Blood Project Group: UK Comparative Audit of Upper Gastrointestinal Bleeding and the Use of Blood. London, UK: British Society of Gastroenterology; 2007. [http://bsg.org.uk/pdf_word_docs/ blood_audit_report_07.pdf].

2. Church NI, Dallal HJ, Masson J, Mowat NA, Johnston DA, Radin E, Turner M, Fullarton G, Prescott RJ, Palmer KR: Validity of the Rockall scoring system after endoscopic therapy for bleeding peptic ulcer: a prospective cohort study. Gastrointest Endosc 2006, 63:606-12.

3. Stanley AJ, Ashley D, Dalton HR, Mowat C, Gaya DR, Thompson E, Warshow U, Groome M, Cahill A, Benson G, Blatchford O, Murray W: Outpatient management of patients with low-risk upper-gastrointestinal haemorrhage: multicentre validation and prospective evaluation. Lancet 2009, 373:42-7.

Changes Clinical Practice

FI000 Factor 4.8 Must Read

Evaluated by lan Beales 26 Feb 2009, John Inadomi 03 Mar 2009

4. Romagnuolo J, Barkun AN, Enns R, Armstrong D, Gregor J: Simple clinical predictors may obviate urgent endoscopy in selected patients with nonvariceal upper gastrointestinal tract bleeding. Arch Intern Med 2007, 167:265-70.

5. Pabinger I, Brenner B, Kalina U, Knaub S, Nagy A, Ostermann H: Prothrombin complex concentrate (Beriplex P/N) for emergency anticoagulation reversal: a prospective multinational clinical trial. J Thromb Haemost 2008, 6:622-31.

6. Scottish Intercollegiate Guidelines Network (SIGN): Management of Acute Upper and Lower Gastrointestinal Bleeding. A National Clinical Guideline. Edinburgh, UK: SIGN; Sept 2008. [http://www.sign.ac.uk/pdf/ sign l05.pdf].

7. Vergara $M$, Calvet $X$, Gisbert JP: Epinephrine injection versus epinephrine injection and a second endoscopic method in high risk bleeding ulcers. Cochrane Database Syst Rev 2007: CD005584.

8. Sung J, Tsoi KK, Lai LH, Wu JC, Lau JY: Endoscopic clipping versus injection and thermo-coagulation in the treatment of non-variceal upper gastrointestinal bleeding: a meta-analysis. Gut 2007, 56: I364-73.

\section{Changes Clinical Practice}

FI000 Factor 6.0 Must Read

Evaluated by lan Beales 09 Apr 2008

9. Marmo R, Rotondano G, Piscopo R, Bianco MA, D'Angella R, Cipolletta L: Dual therapy versus monotherapy in the endoscopic treatment of high-risk bleeding ulcers: a meta-analysis of controlled trials. Am J Gastroenterol 2007, 102:279-89.

10. Maiss J, Dumser C, Zopf Y, Naegel A, Krauss N, Hochberger J, Matthes K, Hahn EG, Schwab D: “Hemodynamic efficacy" of two endoscopic clip devices used in the treatment of bleeding vessels, tested in an experimental setting using the compact Erlangen Active Simulator for Interventional Endoscopy (compactEASIE) training model. Endoscopy 2006, 38:575-80.

I I. Lin HJ, Lo WC, Cheng YC, Perng CL: Endoscopic hemoclip versus triclip placement in patients with high-risk peptic ulcer bleeding. Am J Gastroenterol 2007, 102:539-43.

12. Liou TC, Lin SC, Wang HY, Chang WH: Optimal injection volume of epinephrine for endoscopic treatment of peptic ulcer bleeding. World J Gastroenterol 2006, I 2:3108-I3.
13. Liou TC, Chang WH, Wang HY, Lin SC, Shih SC: Large-volume endoscopic injection of epinephrine plus normal saline for peptic ulcer bleeding. J Gastroenterol Hepatol 2007, 22:996-I002.

14. Lau JY, Sung JJ, Lee KK, Yung MY, Wong SK, Wu JC, Chan FK, Ng EK, You JH, Lee CW, Chan AC, Chung SC: Effect of intravenous omeprazole on recurrent bleeding after endoscopic treatment of bleeding peptic ulcers. N Engl J Med 2000, 343:3 I0-6.

I5. Leontiadis GI, Sharma VK, Howden CW: Proton pump inhibitor therapy for peptic ulcer bleeding: Cochrane collaboration meta-analysis of randomized controlled trials. Mayo Clin Proc 2007, 82:286-96.

16. Murthy S, Keyvani L, Leeson S, Targownik LE: Intravenous versus high-dose oral proton pump inhibitor therapy after endoscopic hemostasis of high-risk lesions in patients with acute nonvariceal upper gastrointestinal bleeding. Dig Dis Sci 2007, 52: $1685-90$.

17. Jensen DM, Pace SC, Soffer E, Comer GM; 315 Study Group: Continuous infusion of pantoprazole versus ranitidine for prevention of ulcer rebleeding: a U.S. multicenter randomized, double-blind study. Am J Gastroenterol 2006, I 0 I:I99|-9; quiz 2170.

18. van Rensburg C, Barkun AN, Racz I, Fedorak R, Bornman PC, Beglinger C, Balanzo J, Deviere J, Kupcinskas L, Luehmann R, Doerfler H, Schafer-Preuss S: Clinical trial: intravenous pantoprazole vs. ranitidine for the prevention of peptic ulcer re-bleeding: a multicentre, multinational, randomized trial. Aliment Pharmacol Ther 2009, 29:497-507.

19. Zargar SA, Javid G, Khan BA, Yattoo GN, Shah AH, Gulzar GM, Sodhi JS, Mujeeb SA, Khan MA, Shah NA, Shafi HM: Pantoprazole infusion as adjuvant therapy to endoscopic treatment in patients with peptic ulcer bleeding: prospective randomized controlled trial. J Gastroenterol Hepatol 2006, 2 I:716-21.

20. Tsibouris P, Zintzaras E, Lappas C, Moussia M, Tsianos G, Galeas T, Potamianos S: High-dose pantoprazole continuous infusion is superior to somatostatin after endoscopic hemostasis in patients with peptic ulcer bleeding. Am J Gastroenterol 2007, 102: I 192-9.

21. Sung J, Barkun A, Kuipers EJ, Mossner J, Jensen D, Stuart R, Lau J, Ahlbourn H, Kilhann J, Lind T: Intravenous esomeprazole for prevention of recurrent peptic ulcer bleeding. Ann Int Med 2009, I 50:455-464.

Changes Clinical Practice

FI000 Factor 4.8 Must Read

Evaluated by lan Beales 06 May 2009, Philip O Katz 06 May 2009

22. Lau JY, Leung WK, Wu JC, Chan FK, Wong VW, Chiu PW, Lee VW, Lee KK, Cheung FK, Siu P, Ng EK, Sung JJ: Omeprazole before endoscopy in patients with gastrointestinal bleeding. $N$ Engl J Med 2007, 356:1631-40.

FI000 Factor 6.4 Must Read

Evaluated by lan Beales 16 May 2007, Pankaj Jay Pasricha 21 May 2007

23. Dorward S, Sreedharan A, Leontiadis GI, Howden CW, Moayyedi P, Forman D: Proton pump inhibitor treatment initiated prior to endoscopic diagnosis in upper gastrointestinal bleeding. Cochrane Database Syst Rev 2006:CD0054I5.

24. Gisbert JP, Calvet X, Feu F, Bory F, Cosme A, Almela P, Santolaria S, Aznarez R, Castro M, Fernandez N, Garcia-Gravalos R, Canete N, Benages A, Montoro M, Borda F, Perez-Aisa A, Pique JM: Eradication of Helicobacter pylori for the prevention of peptic ulcer re-bleeding. Helicobacter 2007, 12:279-86.

25. Gisbert JP, Abraira V: Accuracy of Helicobacter pylori diagnostic tests in patients with bleeding peptic ulcer: a systematic review and meta-analysis. Am J Gastroenterol 2006, I 0 I:848-63.

26. Lanas A, Baron JA, Sandler RS, Horgan K, Bolognese J, Oxenius B, Quan H, Watson D, Cook TJ, Schoen R, Burke C, Loftus S, Niv Y, Ridell R, Morton D, Bresalier R: Peptic ulcer and bleeding events associated with rofecoxib in a 3-year colorectal adenoma chemoprevention trial. Gastroenterology 2007, I 32:490-7. 
27. Garcia Rodriguez LA, Barreales Tolosa L: Risk of upper gastrointestinal complications among users of traditional NSAIDs and COXIBs in the general population. Gastroenterology 2007, 132:498-506.

FI000 Factor 4.8 Must Read

Evaluated by lan Beales 22 Mar 2007, Peter Katelaris II Apr 2007

28. Chan FK, Hung LC, Suen BY, Wu JC, Lee KC, Leung VK, Hui AJ, To KF, Leung WK, Wong VW, Chung SC, Sung JJ: Celecoxib versus diclofenac and omeprazole in reducing the risk of recurrent ulcer bleeding in patients with arthritis. N Engl J Med 2002, 347:2104-10.

29. Chan FK, Wong VW, Suen BY, Wu JC, Ching JY, Hung LC, Hui AJ, Leung VK, Lee VW, Lai LH, Wong GL, Chow DK, To KF, Leung WK, Chiu PW, Lee YT, Lau JY, Chan HL, Ng EK, Sung JJ: Combination of a cyclo-oxygenase-2 inhibitor and a proton-pump inhibitor for prevention of recurrent ulcer bleeding in patients at very high risk: a double-blind, randomised trial. Lancet 2007, 369:1621-6.

30. Lai KC, Chu KM, Hui WM, Wong BC, Hung WK, Loo CK, Hu WH Chan AO, Kwok KF, Fung TT, Wong J, Lam SK: Esomeprazole with aspirin versus clopidogrel for prevention of recurrent gastrointestinal ulcer complications. Clin Gastroenterol Hepatol 2006, 4:860-5.

31. Aronow HD, Steinhubl SR, Brennan DM, Berger PB, Topol EJ, CREDO Investigators: Bleeding risk associated with I year of dual antiplatelet therapy after percutaneous coronary intervention: Insights from the Clopidogrel for the Reduction of Events During Observation (CREDO) trial. Am Heart J 2009, I57:369-74.

Changes Clinical Practice

FI000 Factor 6.0 Must Read

Evaluated by lan Beales 03 Apr 2009

32. Ho PM, Maddox TM, Wang L, Fihn S, Jesse R, Peterson E, Rumsfeld J: Risk of adverse outcomes associated with concomitant use of clopidogrel and proton pump inhibitors following acute coronary symdrome. JAMA 2009, 301:937-44.

Changes Clinical Practice

FI000 Factor 8.I Exceptional

Evaluated by Gregory Lip I 2 Mar 2009, Marrick Kukin 23 Mar 2009, Melvin Cheitlin 08 Apr 2009

33. Ibáñez L, Vidal X, Vendrell L, Moretti U, Laporte JR: Upper gastrointestinal bleeding associated with antiplatelet drugs. Aliment Pharmacol Ther 2006, 23:235-42.

34. Henriksen PA, Palmer K, Boon NA: Management of upper gastrointestinal haemorrhage complicating dual anti-platelet therapy. QJM 2008, I0I:26I-7.

35. Ng FH, Chan P, Kwanching CP, Loo CK, Cheung TK, Wong SY, Kng C, Ng KM, Lai ST, Wong BC: Management and outcome of peptic ulcers or erosions in patients receiving a combination of aspirin plus clopidogrel. J Gastroenterol 2008, 43:679-86. 